\title{
IGF status is altered by tamoxifen in patients with breast cancer
}

\author{
M J Campbell, J V Woodside, J Secker-Walker, A Titcomb, A J C Leathem
}

\begin{abstract}
Aims-An increased concentration of insulin-like growth factor 1 (IGF-1) is an independent risk factor for premenopausal breast cancer. Tamoxifen is thought initially to reduce concentrations of IGF-1 and increase concentrations of the IGF binding proteins. The aim of this study was to compare concentrations of IGF-1, IGF binding protein 1 (IGF-BP1), and IGF-BP3 in patients with breast cancer $(n=14)$ with those seen in control subjects $(n=23)$ and to assess the effect of tamoxifen on IGF status in these patients. Methods-Non-fasting blood samples were collected from patients with breast cancer before surgery and after nine, 18, and 27 months of tamoxifen treatment. The baseline concentrations were compared with those of age and sex matched healthy control subjects.
\end{abstract}

Results-IGF-1, IGF-BP3, and IGF-BP1 concentrations were not significantly different in cases and controls. Tamoxifen treatment significantly increased IGFBP1 after 18 and 27 months (baseline: mean, $21.6 \mathrm{ng} / \mathrm{ml}$; SD, 16.6; 18 months: mean, 52.0 ng/ml; SD, 41.8; p = 0.019; 27 months: mean, $40.7 \mathrm{ng} / \mathrm{ml}$; SD, 24.9; $p=0.043$ ) and IGF-BP3 after nine, 18 , and 27 months (baseline: mean, 3119 ng/ml; SD, 507; nine months: mean, $3673 \mathrm{ng} / \mathrm{ml}$; SD, 476; $p=0.004 ; 18$ months: mean, $3445 \mathrm{ng} / \mathrm{ml}$; SD, 634; $\mathrm{p}=0.034 ; 27$ months: 3409 ng/ml; SD, 501; p = 0.043) when compared with baseline values. IGF-1 was not altered significantly from baseline at any time point. However, the IGF-1 to IGFBP3 ratio was significantly decreased at both nine and 18 months (baseline: mean, 0.058; SD, 0.014; nine months: mean, 0.039; SD, 0.008; $p=0.033 ; 18$ months: mean, 0.044; SD, 0.012; $p=0.01)$. This ratio was not significantly different from baseline at 27 months (mean, 0.054; SD, $0.01 ; \mathrm{p}=0.08)$.

Department of Surgery, Royal Free and University College London Medical School, London, W1W 7EJ, UK

M J Campbell

J V Woodside

J Secker-Walker

A Titcomb

A J C Leathem

Correspondence to: Dr Woodside

j.woodside@qub.ac.uk

Accepted for publication 24 April 2001 BP3 and IGF-BP1 concentrations. It also decreases the IGF-1 to IGF-BP3 ratio but this effect may be limited after long term use. Longer follow up, with larger numbers of patients, should determine when, and for how long, tamoxifen can reduce circulating IGF-1.

(f Clin Pathol: Mol Pathol 2001;54:307-310)

Keywords: breast cancer; tamoxifen; insulin-like growth factor 1; insulin-like growth factor binding proteins

Breast cancer is the most prevalent cancer in women in Western populations. The risk of breast cancer increases greatly with age, and other established hormone related risk factors include early menarche, late age at menopause, and delayed age at first pregnancy. ${ }^{1}$ Family history is also important, although established genetic factors only account for about $5 \%$ of breast cancers in Western populations. ${ }^{2}$

Insulin-like growth factor 1 (IGF-1) is a potent mitogen for breast cancer cell lines. ${ }^{3}$ Increased concentrations of IGF-1 have been found in patients with breast cancer compared with healthy controls. ${ }^{4}$ In addition, healthy subjects with high IGF-1 concentrations, when controlled for binding proteins, have been shown to have an increased risk of breast cancer (RR 7.28, highest $v$ lowest quintile). ${ }^{5}$ It is now accepted that high concentrations of IGF-1 are a risk factor for premenopausal breast cancer.

Tamoxifen, an antioestrogen in use for over 20 years, is the most commonly used agent in the treatment of hormone responsive breast cancer. ${ }^{6}$ Clinical trials have confirmed the benefit of tamoxifen in preventing breast cancer recurrence and improving disease free survival. $^{78}$

Apart from its main action via oestrogen receptors, tamoxifen possesses numerous other plausible mechanisms for controlling tumour growth, such as binding to protein kinase $\mathrm{C},{ }^{9}$ inhibiting ornithine decarboxylase activity, ${ }^{10}$ and inhibiting angiogenesis. ${ }^{11}$ Tamoxifen can act as an antioxidant, ${ }^{12}$ and can suppress the production of transforming growth factor $\alpha$ (TGF- $\alpha$ ) and stimulate the production of TGF- $\beta .^{13} 14$

In addition, tamoxifen initially seems to reduce IGF-1 concentrations ${ }^{15}$ and increase concentrations of its binding proteins, but studies with longitudinal sampling and long term follow up have yet to be carried out.

The aim of our study was to compare concentrations of IGF-1 and its binding proteins in patients with breast cancer with those found in age and sex matched control subjects; in addition, we assessed the longitudinal effect of tamoxifen on IGF status in patients with breast cancer.

\section{Methods}

Non-fasting serum samples were collected before surgery from patients with stage I-III invasive breast cancer, both premenopausal and postmenopausal. Serum samples were collected, again non-fasting, after $<9,<18$, and $<27$ months of tamoxifen treatment at routine surgical outpatient appointments. The baseline concentrations were compared with age and sex matched control subjects recruited from the general population. In the patients with breast cancer, no patient showed evidence of 
Table 1 Baseline concentrations of insulin-like growth factor $1(I G F-1)$, IGF binding protein 1 (IGF-BP1), and $I G F-B P 3$ in patients and controls

\begin{tabular}{llll}
\hline & $\begin{array}{l}\text { Patients } \\
(n=14)\end{array}$ & $\begin{array}{l}\text { Controls } \\
(n=23)\end{array}$ & $p$ Value \\
\hline IGF-1 $(\mathrm{ng} / \mathrm{ml})$ & $166.6(42.0)$ & $194.2(63.4)$ & NS \\
IGF-BP1 $(\mathrm{ng} / \mathrm{ml})$ & $21.6(16.6)$ & $37.9(46.5)$ & NS \\
IGF-BP3 $(\mathrm{ng} / \mathrm{ml})$ & $3119(507)$ & $3211(598)$ & NS
\end{tabular}

Values are mean (SD)

NS, not significant.

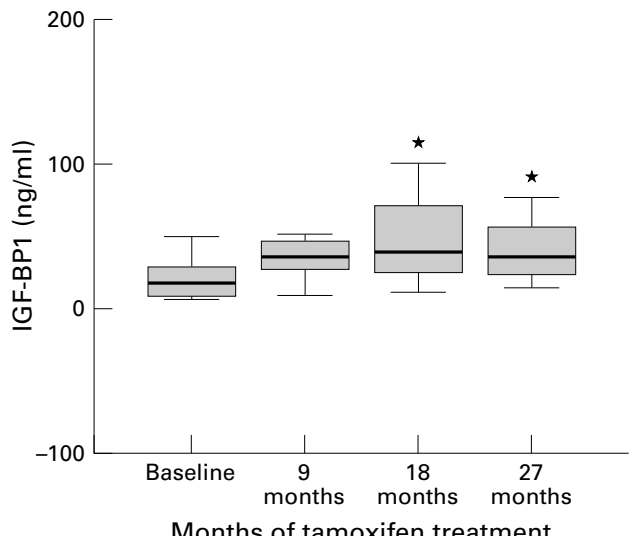

Figure 1 Effect of tamoxifen supplementation on insulin-like growth factor binding protein 1 (IGF-BP1). Values are median (black line) with interquartile ranges (boxed area) and minimum-maximum values (bars). ${ }^{\star} p<0.05$ for differences from baseline; Wilcoxon signed rank test.

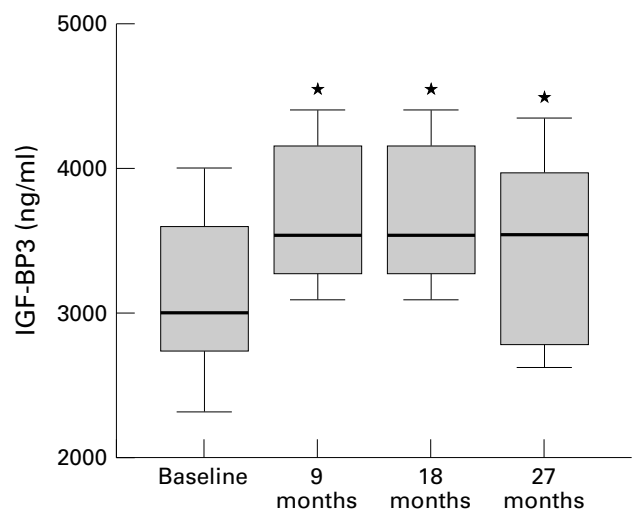

Months of tamoxifen treatment

Figure 2 Effect of tamoxifen supplementation on insulin-like growth factor binding protein 3 (IGF-BP3). Values are median (black line) with interquartile ranges (boxed area) and minimum-maximum values (bars). $\star p<0.05$ for differences from baseline; Wilcoxon signed rank test.

metastatic disease during the treatment period. None of the patients suffered from any other endocrine or malignant disorder during the treatment period. All patients had been prescribed $20 \mathrm{mg}$ of tamoxifen daily and gave written informed consent to participate. Our study was approved by the ethical committee of the Royal Free and University College London Medical School.

\section{LABORATORY METHODS}

Serum was stored at $-80^{\circ} \mathrm{C}$ until analysis. Concentrations of IGF-1, IGF binding protein 1 (IGF-BP1), and IGF-BP3 were measured in

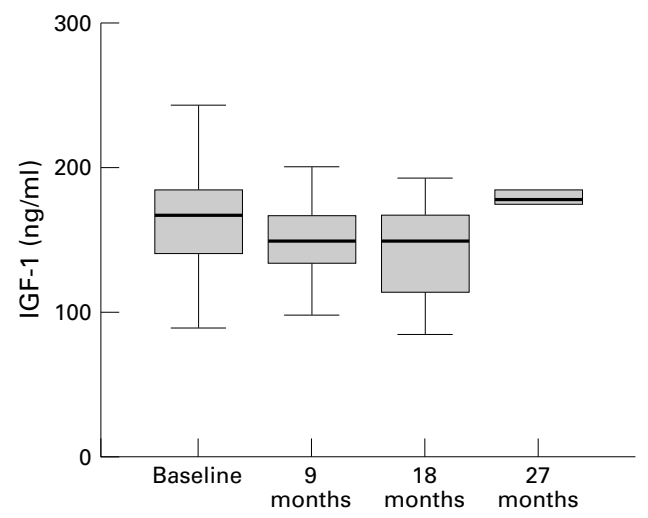

Months of tamoxifen treatment

Figure 3 Effect of tamoxifen supplementation on insulin-like growth factor 1 (IGF-1). Values are median (black line) with interquartile ranges (boxed area) and minimum-maximum values (bars). ${ }^{\star} p<0.05$ for differences from baseline; Wilcoxon signed rank test.

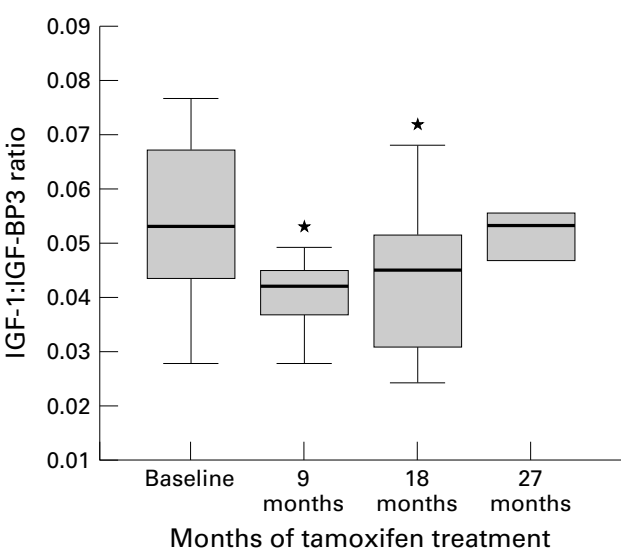

Figure 4 Effect of tamoxifen supplementation on the insulin-like growth factor 1 (IGF-1) to IGF binding protein 3 (IGF-BP3) ratio. Values are median (black line) with interquartile ranges (boxed area) and minimum-maximum values (bars). ${ }^{\star} p<0.05$ for differences from baseline; Wilcoxon signed rank test.

serum by means of enzyme linked immunosorbent assay kits purchased from Diagnostics Systems Laboratories (London, UK).

STATISTICAL METHODS

Owing to the small numbers of subjects involved, non-parametric tests were used throughout. The IGF status of patients with breast cancer compared with healthy controls was analysed using a Mann Whitney U test. Analysis of the change in IGF status at particular time points compared with baseline values was carried out using Wilcoxon signed rank tests. Test results were considered to be significant when $\mathrm{p}<0.05$.

\section{Results}

The mean (SE) patient age was 51.0 (2.7) years (range, 38-70).

Concentrations of IGF-1, IGF-BP1 and IGF-BP3 at baseline did not differ between cases and controls (table 1 ).

The concentrations of the three variables measured were within the expected range reported in the literature. IGF-BP1 was increased significantly after 18 and 27 months of tamoxifen treatment (fig 1). IGF-BP3 was 
significantly increased from baseline at nine, 18, and 27 months (fig 2). IGF-1 was not decreased significantly (fig 3), but the IGF-1 to IGF-BP3 ratio, a commonly used measure of bioavailable IGF- $1,{ }^{5}$ was significantly decreased both at nine and 18 months (fig 4). The IGF-1 to IGF-BP3 ratio was not significantly different from baseline at 27 months.

\section{Discussion}

We found that tamoxifen has the ability to lower bioavailable IGF-1 (calculated as the IGF-1 to IGF-BP3 ratio) for at least 18 months. Although concentrations of IGF-1 were not reduced significantly, concentrations of its major binding protein IGF-BP3 increased significantly, thereby reducing the amount of IGF-1 available. However, this ratio of IGF-1 to IGF-BP3 was not significantly reduced from baseline at 27 months, so that the effect of longer treatment remains to be elucidated. Tamoxifen also significantly increased concentrations of IGF-BP1 from baseline after 18 months of treatment. This increase has also been seen in other studies. ${ }^{16}{ }^{17}$

Our finding of a lack of effect on IGF-1 concentrations is surprising because other studies have shown a reduction in IGF-1 by tamoxifen. ${ }^{15}{ }^{16}$ This might be the result of the small numbers of patients in our study group or population selection. However, another study ${ }^{17}$ also failed to show an effect on IGF-1 at a median follow up of 29 months. These investigators had seen a significant decrease in IGF-1 values after six months of tamoxifen treatment and their data point to a limited effect after long term treatment. Our data also indicate an initial (although non-significant) reduction in IGF-1, which is lost as follow up time increases. This indicates a potentially important effect of duration of treatment on outcome and highlights the need for further longitudinal studies with strictly timed follow up periods.

We also found no differences between cases and controls in terms of IGF-1, IGF-BP1, and IGF-BP3 concentrations. Again, this is surprising because earlier studies have revealed differences in similar groups. A lack of such a finding may again simply reflect a lack of numbers. We were unable to divide our subjects into premenopausal and postmenopausal groups, again owing to the small sample size, and this may have been reflected in our results because IGF-1 values have been shown to be a stronger predictor of breast cancer risk in premenopausal than in postmenopausal women. ${ }^{5}$

Our study was not placebo controlled, and therefore subjects were not randomised to a treatment regimen; a placebo controlled study would have distinct design advantages over the one described here. However, controversies over the ethical implications of such trials have been the subject of recent collaborative reports. ${ }^{18}$ An earlier placebo controlled, long term study showed a significant reduction in IGF-1 after a mean follow up of 27 months (minimum follow up three months) but longitudinal samples were not taken. ${ }^{15}$ It may be possible for samples from the ongoing tamoxifen prevention trials (such as IBIS) to be used in further research into the effects of tamoxifen on the IGF system. ${ }^{19}$ The samples used in our study were non-fasting and this may be important because values may fluctuate according to nutrient intake. ${ }^{20}$

Changes in serum concentrations of IGF-1 have been shown to correlate positively with serum oestradiol concentrations in menstruating women. ${ }^{21}$ This agrees with findings that IGF-1 can vary over the menstrual cycle, with significantly lower values being found during the menstrual phase than the follicular and luteal phases. ${ }^{22}$ Although other studies found that IGF-1 concentrations were dependent on the menstrual cycle phase they considered this to be a fairly minor variation. ${ }^{23}$ Our study did not take into account the effect of the menstrual cycle and it may be important to control for this in future work.

The mechanism by which tamoxifen alters IGF status has not been fully elucidated. However, tamoxifen is thought to alter IGF-1 values by reducing the production of growth hormone from the pituitary, thereby lowering the amount of IGF-1 that is produced by the liver and released into the circulation. It also has direct action as an antioestrogen on breast cancer cells and appears to alter the amount of IGF-1 and binding proteins released by the cells themselves. ${ }^{13}{ }^{15}$

\section{Conclusion}

Patients with breast cancer had similar concentrations of IGF-1, IGF-BP1, and IGF-BP3 to those seen in healthy control subjects in this pilot study. Tamoxifen can increase IGF-BP1, IGF-BP3, and reduce the IGF-1 to IGF-BP3 ratio, and these alterations may contribute to the therapeutic benefits of tamoxifen. The long term effects of tamoxifen use on IGF status remain to be established. Longer follow up with larger numbers of patients should determine when, and for how long, tamoxifen can reduce circulating IGF-1.

This study was funded by Action Against Breast Cancer, registered charity number 1020967 .

1 Bernstein L, Ross PK. Endogenous hormones and breast cancer risk. Epidemiol Rev 1993;15:48-65.

2 McPherson K, Steel CM, Dixon JM. ABC of breast diseases. Breast cancer-epidemiology, risk factors and genetics. BMF 2000;321:624-8.

3 Karey KP, Sibarsu DA. Differential responsiveness of human breast cancer cell line MCF-7 and T47D to growth factors and 17-beta estradiol. Cancer Res 1988;48:4083-92.

4 Bruning PF, van Doorn J, Bonfrer JMG, et al. Insulin-like growth-factor-binding protein 3 is decreased in early-stage operable pre-menopausal breast cancer. Int 7 Cancer 1995; 62:266-70.

5 Hankinson SE, Willett WC, Colditz GA, et al. Circulating concentrations of insulin-like growth factor-1 and risk of breast cancer. Lancet 1998;351:1393-6.

6 Katzenellenbogen BS, Motano MM, Ekena K, et al. Antiestrogens: mechanisms of action and resistance in breast cancer. Breast Cancer Res Treat 1997;44:23-38

7 Early Breast Cancer Trialists Collaborative Group. Effect of adjuvant tamoxifen and of cytotoxic therapy on mortality in early breast cancer. An overview of 61 randomized trials among 28,896 women. $\mathrm{N} \mathrm{Engl} \mathrm{F} \mathrm{Med} \mathrm{1988;319:1681-92.}$

8 Baum M. Tamoxifen - the treatment of choice. Why look for alternatives? BrF Cancer 1998;78:1-4.

9 O'Brian DA, Liskamp R, Solomon DH, et al. Inhibition of protein kinase C by Tamoxifen. Cancer Res 1985;45:24625.

10 Thomas T, Trend B, Butterfield JR, et al. Regulation of ornithine decarboxylase gene expression in MCF-7 breast cancer cells by antiestrogens. Cancer Res 1989;49:5852-87.

11 Gagliardi A, Collins DC. Inhibition of angiogenesis by antiestrogens. Cancer Res 1993;53:533-5. 
12 Wei HC, Cai QY, Tian LQ, et al. Tamoxifen reduces endogenous and UV light-induced oxidative damage to DNA lipid and protein in vitro and in vivo. Carcinogenesis :1013-18.

13 Winston R, Kao PC, Kiang DT. Regulation of insulin-like growth factors by antiestrogen. Breast Cancer Res Treat 1994;31:107-15.

14 Carmichael PL, Pole JCM, Neven P. Modulation of endometrial transforming growth factor beta by tamoxifen Eur 7 Cancer 2000;36:S42-3.

15 Pollak M, Costantino J, Polychronakos C, et al. Effect of Tamoxifen on serum insulin like growth factor-1 levels in stage I breast cancer patients. F Natl Cancer Inst 1990;82:1693-7.

16 Helle SI, Holly JMP, Tally M, et al. Influence of treatment with Tamoxifen and change in tumour burden on the IGF system in breast cancer patients. Int F Cancer 1996;69:335-

17 Lahti EI, Knip M, Laatikainen TJ. Plasma insulin-like growth factor- 1 and its binding proteins 1 and 3 in growth factor- 1 and its binding proteins 1 and 3 in
postmenopausal patients with breast cancer receiving long postmenopausal patients with breast cancer
18 Fisher B, Powles TJ, Pritchard KJ. Tamoxifen for the prevention of breast cancer. Eur $\mathcal{F}$ Cancer 2000;36:142-50.

19 Cuzick J. A brief review of the current breast cancer prevention trails and proposals for future trials. Eur $\mathcal{F}$ Cancer 2000;36:1298-302.

20 Clemmons DR, Underwood LE. Nutritional regulation of IGF-1 and IGF binding proteins. Anпu Rev Nutr 1991;11: 393-412.

21 Massa G, Igoul A, Rombauts L, et al. Effect of oestrogen status on serum levels of growth hormone-binding protein and insulin-like growth factor-1 in non-pregnant and pregnant women. Clin Endocrinol 1993;39:569-75.

22 Helle SI, Anker G, Meadows KA, et al. Alterations in the insulin-like growth factor system during the menstrual cycle in normal women. Maturitas 1998;28:259-65.

23 Juul A, Anker G, Pederson AT, et al. Changes in serum concentrations of growth hormone, insulin, insulin-like growth factor and insulin-like growth factor-binding proteins 1 and 3 and urinary growth hormone excretion during the menstrual cycle. Hum Reprod 1997;12:2123-8.

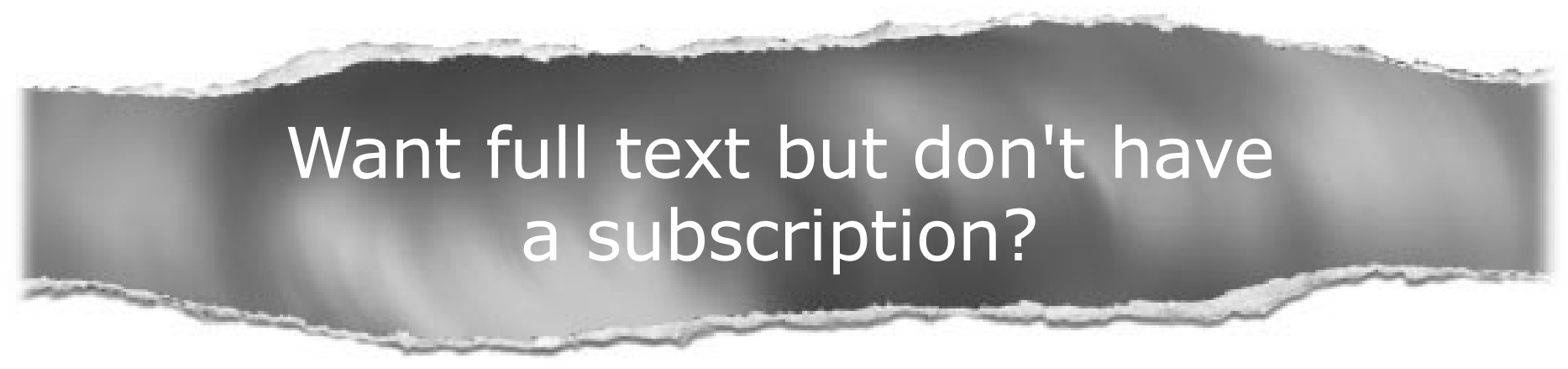

Pay per view

For just \$8 you can purchase the full text of individual articles using our secure online ordering service. You will have access to the full text of the relevant article for 48 hours during which time you may

download and print the pdf file for personal use.

\section{www.jclinpath.com}

